\title{
DESAIN PELETAKAN PENYANGGA DAN EVALUASI TEGANGAN PADA SISTEM PERPIPAAN FLUIDA MASSECUITE DARI REHEATER MENUJU FEED MIXER
}

\author{
Pekik Mahardhika \\ Program Studi D4 Teknik Perpipaan, Politeknik Perkapalan Negeri Surabaya \\ Jl. Teknik Kimia Kampus ITS, Keputih Sukolilo Surabaya 60111 \\ Email: pekikmahardhika@ppns.ac.id
}

\begin{abstract}
Abstrak
Industri gula merupakan industri yang sangat penting di Indonesia untuk memenuhi kebutuhan pasar domestik. Salah satu produk dari perusahaan gula adalah gula kristal putih. Pada proses produksi gula putih terdapat fluida yang bernama Massecuite. Massecuite adalah fluida campuran antara kristal gula dan air. Massecuite dapat menimbulkan endapan dan penyumbatan pada jalur perpipaan dari reheater menuju feed mixer. Jalur perpipaan dari reheater menuju feed mixer sudah dilakukan desain ulang. Tetapi jalur perpipaan tersebut belum didesain peletakan penyangga dan dievaluasi tegangan pipa. Sehingga jalur perpipaan tersebut perlu didesain peletakan penyangga dan evaluasi tegangan pipa. Evaluasi tegangan pipa mengacu pada ASME B31.3 Perpipaan Proses. Evaluasi ini bertujuan untuk memastikan desain jalur perpipaan sesuai persyaratan ASME B31.3. Hasil evaluasi menunjukkan bahwa bahwa tegangan pada jalur perpipaan dari reheater menuju feed mixer masih memenuhi kriteria ASME B31.3. Desain jalur perpipaan dari reheater menuju feed mixer dapat dinyatakan aman.
\end{abstract}

Kata Kunci: ASME B31.3, Endapan, Massecuite, Tegangan Pipa

\begin{abstract}
The sugar industry is a very important industry in Indonesia to meet the needs of the domestic market. One of the products of the sugar company is white crystal sugar. In the process of producing white sugar there is a fluid called Massecuite. Massecuite is a mixture of fluid crystals of sugar and water. Massecuite can cause sedimentations and blockages in the pipeline from the heater to the feed mixer. The line pipe from the reheater to the feed mixer has been redesigned. But the line pipe has not been designed for laying penyangga and evaluate piping stress. So that the line pipe needs to be designed for laying penyangga and evaluate piping stress. Evaluation of piping stress accordance to ASME B31.3 Process Piping. This evaluation aims to ensure that the line pipe design comply with ASME B31.3 requirements. The evaluation results evidence that the stress in the line pipe from the reheater to the feed mixer still meets the ASME B31.3 criteria. The line pipe design from the reheater to the feed mixer can be declared safe.
\end{abstract}

Keywords: ASME B31.3, Sedimentations, Massecuite, Piping Stress

\section{PENDAhuluan}

Industri gula merupakan industri yang sangat penting di Indonesia untuk memenuhi kebutuhan pasar domestik. Pemerintah memiliki tantangan menjawab kebutuhan gula masyarakat Indonesia yang terus bertambah (Okezone.com, 2020). Peningkatan produksi merupakan bagian dari yang diharapkan pemerintah kepada perusahaan gula. Salah satu produk dari perusahaan gula adalah gula kristal putih. Pada proses produksi gula putih terdapat fluida yang bernama Massecuite.
Massecuite adalah fluida campuran antara kristal gula dan air. Distribusi fluida massecuite dari reheater menuju feed mixer menggunakan sistem perpipaan. Pada proses distribusi melalui sistem perpipaan memiliki peran yang sangat penting karena sebagai sarana transportasi nira. Pada sistem perpipaan tersebut memiliki tekanan operasi 6,4 bar (92,82 psi), temperatur $55^{\circ} \mathrm{C}(131 \mathrm{~F})$. Massecuite dapat menimbulkan endapan dan penyumbatan pada jalur perpipaan dari reheater menuju feed mixer. Jalur perpipaan dari reheater menuju feed 
mixer sudah dilakukan desain ulang. Pada hasil desain ulang menunjukkan bahwa dengan mengurangi belokan dapat mengurangi gaya gesek sehingga kecepatan cenderung stabil serta nilai headloss dan pressure drop lebih kecil dari pada desain awal sehingga kemungkinan kecil untuk terjadi endapan.

Makalah ini melanjutkan penelitian sebelumnya yang membahas tentang desain jalur perpipaan dari reheater menuju feed mixer agar tidak mudah terjadi endapan (Laras, Santoso, \& Ariwiyono, 2018). Pada makalah ini dilakukan perancangan peletakan penyangga karena berat pipa dan fluida tersebut merupakan beban sustain sehingga pipa memerlukan penyangga (Mahardhika, 2017). Perancangan peletakan penyangga dengan melakukan perhitungan jarak maksimum yang diijinkan antar penyangga pipa. Penentuan jarak maksimum yang diijinkan antar penyangga pipa sangatlah penting karena mempertimbangkan keselamatan serta biaya (ereksi pipa) (Vakharia \& Farooq, 2009). Pada makalah ini juga dilakukan pemodelan dan simulasi jalur perpipaan dari massecuite dari reheater menuju feed mixer untuk mendapatkan nilai tegangan pipa yang terjadi apakah masih memenuhi kriteria ASME B31.3. Besarnya nilai tegangan tidak boleh lebih besar dari tegangan yang diijinkan ASME B31.3 (ASME, 2016). Jika tegangan yang terjadi melebihi tegangan yang diijinkan code maka bisa terjadi deformasi pipa ataukah kegagalan sistem perpipaan (Mahardhika, Julianto, Indartono, \& Kusuma, 2018). Sehingga dalam proses perancangan sistem perpipaan diperlukan analisa tegangan statis ataupun dinamis untuk menjamin keamanan rancangan dan operasional pipa (Mahardhika, 2018). Analisa tegangan merupakan metode terpenting untuk meyakinkan dan menetapkan secara numerik bahwa sistem perpipaan dalam engineering adalah aman (Chamsudi, 2005) (Kannappan, 1986). Fleksibilitas dalam perencanaan dan desain pada sebuah sistem perpipaan harus dirancang agar mampu menahan beban yang terjadi karena berhubungan dengan tegangan pipa (Hasan, Santoso, \& Mahardhika, 2017).

\section{METODOLOGI}

\subsection{Data Penelitian}

Data penelitian yang diperlukan tercantum pada Tabel 1 dan Tabel 2 berikut:
Tabel 1. Spesifikasi pipa

\begin{tabular}{|c|c|}
\hline Data & Spesifikasi \\
\hline Material Pipa & A53 Grade B \\
\hline NPS & 6 \\
\hline Schedule & 40 \\
\hline $\mathrm{t}$ (in) & 0,28 \\
\hline $\mathrm{OD}$ (in) & 6,625 \\
\hline ID (in) & 6,065 \\
\hline$\rho$ pipa $\left(\mathrm{lb} / \mathrm{in}^{3}\right)$ & 0,283 \\
\hline Modulus Elastisitas Pipa (psi) & $29,1 \times 10^{6}$ \\
\hline Thermal cofficient (in/ft) & 0,01 \\
\hline
\end{tabular}

Tabel 2. Data Sifat Fluida (massecuite)

\begin{tabular}{|c|c|c|}
\hline Data & Nilai & Satuan \\
\hline Tekanan Internal $(\mathrm{P})$ & 92,82 & $\mathrm{psi}$ \\
\hline Kapasitas $(\mathrm{Q})$ & 741,6 & $\mathrm{ft}^{3} / \mathrm{h}$ \\
\hline Temperatur $(\mathrm{T})$ & 131 & $\mathrm{~F}$ \\
\hline Massa Jenis $(\rho)$ & 0,05 & $\mathrm{lb} / \mathrm{in}^{3}$ \\
\hline
\end{tabular}

\subsection{Tinjauan Pustaka}

Perpipaan kritis adalah semua jalur pipa yang harus dipertimbangkan atau diperhitungkan dalam analisa tegangan pipa, karena temperatur fluida dan diameter pipa memenuhi ketetapan dalam kriteria. Perpipaan tidak kritis adalah semua jalur pipa tidak dipertimbangkan atau diperhitungkan dalam analisa tegangan pipa, karena temperatur fluida dan diameter pipa tidak memenuhi sebagaimana yang ditetapkan dalam kriteria (Chamsudi, 2005). Kriteria untuk jalur perpipaan krtitis merupakan fungsi diameter pipa dan temperatur yang ditunjukkan Gambar 1. Jalur perpipaan dari massecuite dari reheater menuju feed mixer dimasukkan kategori peralatan statis.

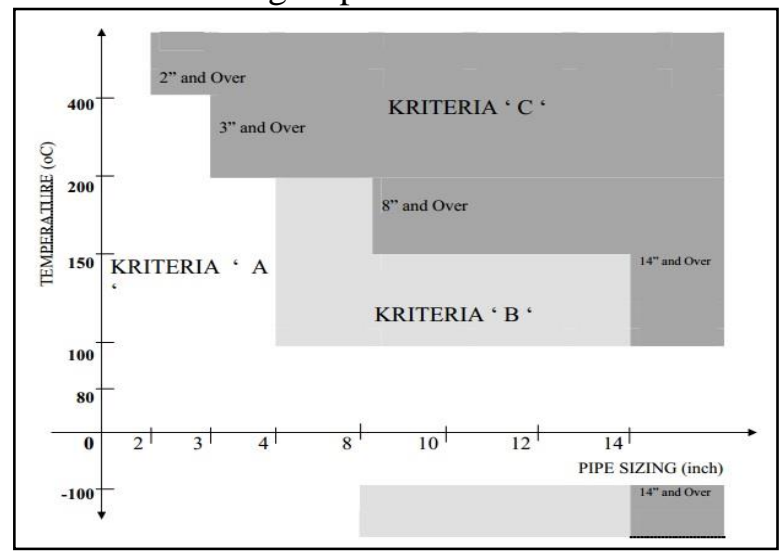

Gambar 1. Kriteria jalur perpipaan kritis untuk pipa yang terhubung dengan peralatan statis (Chamsudi, 2005)

Keterangan:

Kriteria A : Tidak perlu dianalisa.

Kriteria B : Harus dikoreksi dengan metode 
Perhitungan sederhana.

Kriteria C : Detail analisa harus dihitung dengan bantuan software komputer.

Antar penyangga pipa harus diberi jarak berdasarkan 3 pertimbangan berikut ini (Crocker, 1945):

- Kemampuan penempatan penyangga di lokasi yang inginkan.

- Batas jarak yang diijinkan.

- Menghindari tegangan ijin yang berlebihan dan konsentrasi beban antara penyangga.

Penentuan jarak maksimum yang diijinkan antar penyangga untuk sistem perpipaan horisontal dibatasi 3 faktor utama yaitu berdasarkan tegangan tekuk, defleksi vertikal, dan frekuensi alami (Kannappan, 1986).

Persamaan untuk menentukan jarak maksimum yang diijinkan antar penyangga pipa diasumsikan menggunakan penyangga pinned/simply yaitu (Kannappan, 1986):

- Berdasarkan batasan tegangan:

$$
L s=\frac{\sqrt{0,33 . Z . S}}{\mathrm{w}}
$$

- Berdasarkan batasan defleksi:

$$
L s=\frac{\sqrt[4]{\Delta \cdot E . I}}{22,5 . \mathrm{w}}
$$

Persamaan untuk menentukan jarak maksimum yang diijinkan antar penyangga pipa diasumsikan menggunakan penyangga fixed/clamp yaitu (Kannappan, 1986):

- Berdasarkan batasan tegangan:

$$
L s=\frac{\sqrt{0,4 . Z . S}}{\mathrm{w}}
$$

- Berdasarkan batasan defleksi:

$$
L s=\frac{\sqrt[4]{\Delta \cdot E . I}}{13,5 . \mathrm{w}}
$$

Keterangan:

Ls = Maximum allowable pipe span $(\mathrm{ft})$

$\mathrm{S} \quad=$ Tegangan pipa yang dijinkan (psi)

$\mathrm{Z} \quad=$ Section Modulus pipa $\left(\mathrm{in}^{3}\right)$

$\mathrm{w}=$ Berat total pipa per satuan panjang (lb/in)

$\Delta \quad=$ Defleksi pipa yang diijinkan (in)

I = Momen inersia pada bentangan pipa (in $\left.{ }^{4}\right)$

$\mathrm{E}=$ Modulus elastisitas pada temperatur desain

$$
\text { (psi) }
$$

Persamaan untuk menghitung total berat pipa adalah (Kannappan, 1986):

$$
\begin{array}{ll}
\mathrm{w}_{\text {pipa }} & =\frac{\pi}{4} \cdot\left(\mathrm{D}^{2}-\mathrm{d}^{2}\right) \cdot \rho_{\text {pipa }} \cdot \mathrm{L}(5) \\
\mathrm{W}_{\text {fluida }} & =\frac{\pi}{4} \cdot\left(d^{2}\right) \cdot \rho_{\text {fluida }} \cdot \mathrm{L} \\
\mathrm{W}_{\text {insulasi }} & =\frac{\pi}{4} \cdot\left(\mathrm{D}_{\text {ins }}^{2}-\mathrm{D}^{2}\right) \cdot \rho_{\text {ins }} \cdot \mathrm{L}(7) \\
\mathrm{w}_{\text {total }} & =\mathrm{w}_{\text {pipa }}+\mathrm{w}_{\text {fluida }}+\mathrm{w}_{\text {insulasi }}(8)
\end{array}
$$

$$
\text { Jumlah penyangga }(\mathrm{NOS})=\frac{L}{L S}
$$

Keterangan:

$$
\begin{array}{ll}
\mathrm{D} & =\text { Diameter luar pipa (in) } \\
\mathrm{d} & =\text { Diameter dalam pipa (in) } \\
\mathrm{W}_{\text {pipa }} & =\text { Berat pipa (lb) } \\
\mathrm{W}_{\text {fluida }} & =\text { Berat fluida (lb) } \\
\mathrm{W}_{\text {insulasi }} & =\text { Berat insulasi (lb) } \\
\mathrm{W}_{\text {total }} & =\text { Berat total pipa (lb) } \\
\mathrm{L} & =\text { Panjang pipa (in) }
\end{array}
$$

Melakukan pengecekan fleksibilitas sistem perpipaan dengan pertimbangan kekuatan, reaksi bahaya, dan tingkat bahaya fluida, dan beberapa pendapat sehingga dibentuklah batas temperatur, tekanan, dan ukuran pipa. Pendekatan sistem perpipaan yang dikategorikan untuk dianalisa fleksibilitasnya sebagai berikut (Kellogg, 1956):

a. Maksimum temperatur operasi material melebihi $800 \mathrm{~F}$.

b. Tekanan layanan melebihi 15 psi.

c. Nominal Pipe Size (NPS) melebihi 6 inch. Jika,

$$
\frac{D \cdot y}{(L-U)^{2}} \leq \frac{30 \cdot S A}{E a}
$$

Maka tidak perlu dilakukan formal analysis karena jalur pipa fleksibel (Kannapan, 1986).

Keterangan:

$\mathrm{D}=$ Nominal Pipe Size (in)

$\Delta=$ Total perpindahan yang dihasilkan (in)

$\mathrm{L}=$ Pertambahan panjang di antara anchor

(ft)

$\mathrm{U}=$ Jarak anchor $(\mathrm{ft})$

$\mathrm{S}_{\mathrm{A}}=$ Allowable stress range $(\mathrm{psi})$

$\mathrm{E}_{\mathrm{a}}=$ Modulus Elastisitas pada kondisi dingin (psi)

Tabel 3 adalah nilai stress range reduction factors berkaitan dengan jumlah siklus suatu sistem perpipaan.

Tabel 3. Stress Range Reduction Factors

\begin{tabular}{|l|c|}
\hline $\begin{array}{l}\text { Number of equivalent } \\
\text { full temperatur cycles }(\boldsymbol{N})\end{array}$ & $\mathbf{f}$ \\
\hline 7000 dan di bawahnya & 1,0 \\
\hline $7000-14000$ & 0,9 \\
\hline $14000-22000$ & 0,8 \\
\hline $22000-45000$ & 0,7 \\
\hline $45000-100000$ & 0,6 \\
\hline 100000 dan di atasnya & 0,5 \\
\hline
\end{tabular}

Salah satu jenis tegangan pipa adalah tegangan akibat pembebanan sustain. Tegangan akibat beban sustain disebabkan oleh beban yang bekerja secara terus menerus atau kontinyu selama sistem perpipaan tersebut beroperasi pada kondisi normal (Paul R Smith; Thomas J Van Laan, 1987). Besarnya nilai tegangan tidak boleh lebih besar dari 
tegangan yang diijinkan ASME B31.3 (ASME, 2016).

$$
S L=\frac{F a x}{A m}+\frac{M b}{Z}+\frac{P . d o}{4 t} \leq S H
$$

Keterangan:

$\mathrm{F}_{\mathrm{ax}} \quad=$ Gaya aksial karena beban tetap (lb)

$\mathrm{Am}=$ Luas permukaan pipa $\left(\mathrm{in}^{2}\right)$

$\mathrm{Mb} \quad=$ Momen bending (lb.in)

$\mathrm{Z} \quad=$ Section modulus $\left(\mathrm{in}^{3}\right)$

$\mathrm{P} \quad=$ Tekanan dalam pipa (psi)

do $\quad=$ Diameter luar pipa (in)

$\mathrm{t} \quad=$ Tebal pipa (in)

SL = Tegangan longitudinal (psi)

$\mathrm{SH} \quad=$ Tegangan yang diijinkan/ Code Allowable stress (psi)

\subsection{Metode}

Metode penelitian adalah tahapan pengerjaan suatu penelitian, agar dapat memperoleh hasil yang baik untuk mencapai tujuan penelitian yang direncanakan/ dirancang. Tahapan pengerjaan penelitian meliputi penentuan jalur kritis, penentuan jarak maksimum yang diijinkan antar penyangga pipa, perhitungan fleksibilitas pipa, dan pemodelan \& simulasi tegangan pipa menggunakan software Autopipe. Kemudian nilai tegangan yang sudah disimulasi disesuaikan dengan kriteria penerimaan ASME B31.3. Kriteria penerimaan merupakan acuan yang digunakan untuk memastikan keselamatan dan keamanan sistem perpipaan sesuai dengan peraturan. Tahapan pengerjaan ditampilkan pada diagram alir berikut ini:

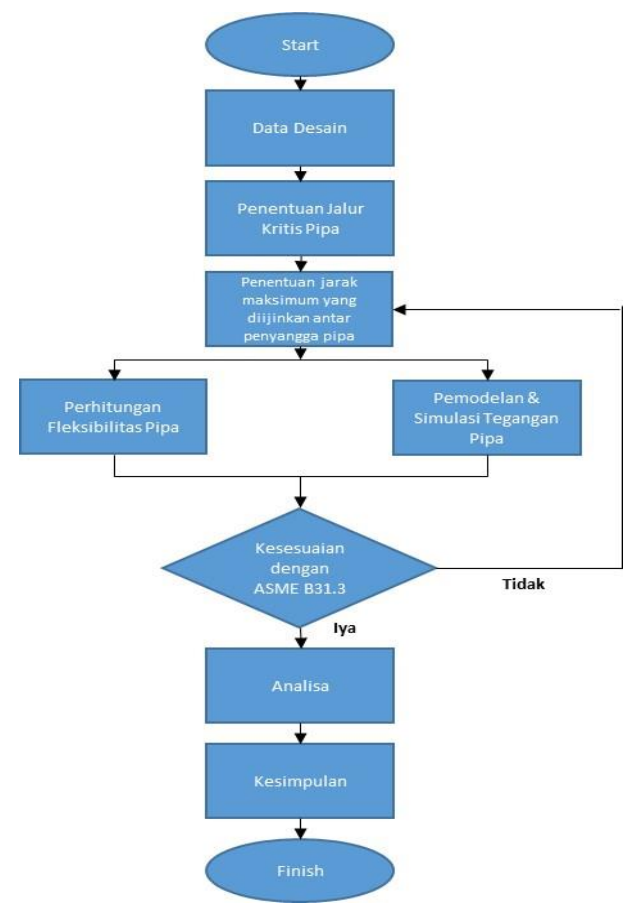

Gambar 2. Diagram Alir Penelitian
Data pendukung pada penelitian ini adalah gambar isometri jalur perpipaan dari reheater menuju feed mixer dan data penelitian sebelumnya. Gambar isometri ditampilkan pada Gambar 3 berikut:
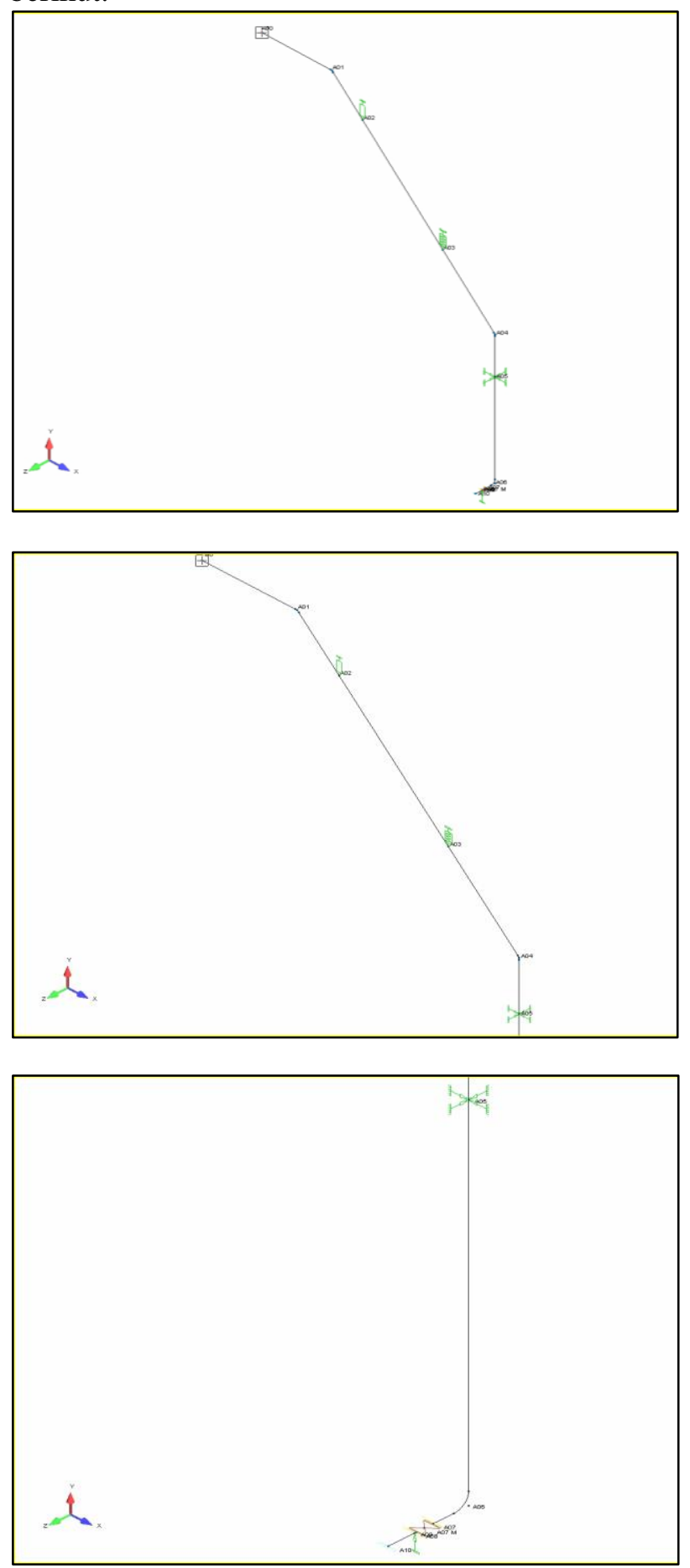

Gambar 3. Isometri Jalur Perpipaan Dari Reheater Menuju Feed Mixer

\section{HASIL DAN PEMBAHASAN}

- Penentuan kriteria daftar jalur kritis pipa Pada penentuan kriteria jalur kritis pipa yang disesuaikan dengan spesifikasi pipa pada Tabel 1 dan dihubungkan dengan 
Gambar 1, maka jalur perpipaan dari reheater menuju feed mixer dikategorikan kriteria B. Kriteria B memiliki arti bahwa jalur perpipaan dari reheater menuju feed mixer termasuk jalur pipa yang kritis yang harus dianalisa dan dikoreksi dengan perhitungan sederhana.

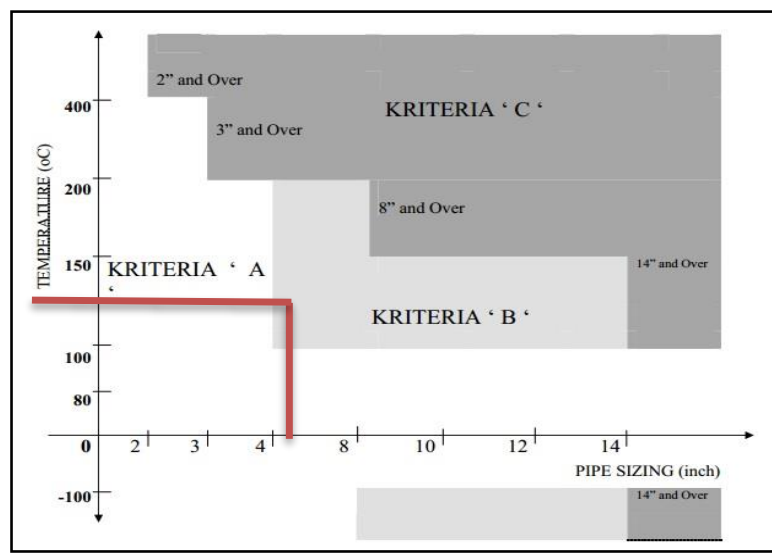

Gambar 3. Hasil Penentuan Daftar Pipa Kritis

- Penentuan jarak maksimum yang diijinkan antar penyangga pipa.

Perhitungan berat total pipa

$$
\begin{aligned}
\mathrm{W}_{\text {pipa }}= & \frac{\pi}{4} \cdot\left(6,625^{2}-6,065^{2}\right) \cdot 0,283 \cdot 12= \\
& 18,95 \frac{\mathrm{lb}}{\mathrm{ft}} \\
\mathrm{W}_{\text {fluida }}= & \frac{\pi}{4} \cdot\left(6,065^{2}\right) \cdot 0,05 \cdot 12=17,32 \frac{\mathrm{lb}}{\mathrm{ft}} \\
\mathrm{W}_{\text {total }} & =\mathrm{W}_{\text {pipa }}+\mathrm{W}_{\text {fluida }} \\
& =18,95 \mathrm{lb} / \mathrm{ft}+17,32 \mathrm{lb} / \mathrm{ft} \\
& =36,27 \mathrm{lb} / \mathrm{ft}
\end{aligned}
$$

Berat total pipa adalah $36,27 \mathrm{lb} / \mathrm{ft}$

Perhitungan jarak maksimum yang diijinkan antar penyangga pipa.

Berdasarkan batasan tegangan

$\mathrm{Z}=8,50 \mathrm{in}^{3}$

$\mathrm{S}=20000 \mathrm{psi}$

Ls $=\frac{\sqrt{0,33 . Z . S}}{\mathrm{w}}$

Ls $=\frac{\sqrt{0,33.8,50.20000}}{36,27}$

Ls $=39,32 \mathrm{ft}$

Berdasarkan batasan defleksi

$\Delta=\frac{3}{8}$ in

$\mathrm{E}=29,1 \times 10^{6} \mathrm{psi}$

$\mathrm{I}=28,1 \mathrm{in}^{4}$

Ls $=\frac{\sqrt[4]{\Delta \text {.E.I }}}{22,5 . w}$

LS $=\frac{\sqrt[4]{\frac{3}{8} \cdot 29,1 \times 10^{6} \cdot 28,1}}{22,5 \cdot 36,27}$

Ls $=24,76 \mathrm{ft}$
Pada perhitungan jarak maksimum yang diijinkan antar penyangga pipa berdasarkan batasan tegangan dan batasan defleksi dipilihlah jarak maksimum yang diijinkan antar penyangga pipa adalah yang paling kecil (Kannappan, 1986). Jarak maksimum yang diijinkan antar penyangga pipa berdasarkan batasan defleksi yang dipilih yaitu $24,76 \mathrm{ft}$ dan diambil $24 \mathrm{ft}$. Jumlah penyangga yang dibutuhkan: $\frac{96,97}{24} \approx 4$ buah.

- Perhitungan fleksibilitas pipa

$\Delta \mathrm{x}=(14,81+48,78) \mathrm{ft} \mathrm{x} 0,01 \mathrm{in} / \mathrm{ft}$ $=0,6259 \mathrm{in}$

$\Delta \mathrm{y}=(29,25) \mathrm{ft} \times 0,01 \mathrm{in} / \mathrm{ft}$ $=0,2925 \mathrm{in}$

$\Delta \mathrm{z}=(4,12) \mathrm{ft} \times 0,01 \mathrm{in} / \mathrm{ft}$ $=0,0412 \mathrm{in}$

$\mathrm{y}=\sqrt{(0,6259)^{2}+}(0,2925)^{2}+$ $(0,0412)^{2}$ $=0,6920 \mathrm{in}$

$\mathrm{L}=96,96 \mathrm{ft}$

$\mathrm{U}=\sqrt{(63,59)^{2}+}(29,25)^{2}+(4,12)^{2}$ $=70,115 \mathrm{ft}$

$\mathrm{S}_{\mathrm{c}}=20000 \mathrm{psi}$

$\mathrm{S}_{\mathrm{h}}=20000 \mathrm{psi}$

$\mathrm{f}=1,0$ (untuk siklus 7000 dan di bawahnya)

$\mathrm{S}_{\mathrm{A}}=\mathrm{f}\left(1,25 \cdot \mathrm{S}_{\mathrm{c}}+0,25 \cdot \mathrm{S}_{\mathrm{h}}\right)$

$$
=1,0(1,25.20000+0,25.20000)
$$$$
=30000 \mathrm{psi}
$$

$\frac{D . y}{(L-U)^{2}} \leq \frac{30 . S A}{E a}$

$\frac{6.0,6920}{(96,96-70,115)^{2}} \leq \frac{30.30000}{29,1 \times 10^{6}}$ $0,0057 \leq 0,0309$

Sehingga pipa tersebut fleksibel dan tidak perlu dilakukan formal analysis. Tetapi jalur perpipaan tersebut tetap akan dilakukan evaluasi lebih lanjut untuk memastikan jalur tesebut aman.

- Pemodelan dan Simulasi Tegangan Pipa

Parameter yang digunakan dalam proses simulasi meliputi material pipa, NPS, Schedule, sifat mekanik material, densitas fluida, temperatur, dan tekanan. Gambar 4 menunjukkan hasil pemodelan dan simulasi tegangan pipa pada jalur perpipaan dari reheater menuju feed mixer. Hasil pemodelan dan simulasi menunjukkan bahwa nilai tegangan desain pipa masih di bawah tegangan yang diijinkan 20000 psi. Nilai tegangan yang diijinkan tersebut digunakan sebagai acuan untuk menyatakan apakah tegangan yang terjadi masih 
dalam kondisi aman. Kode load combination yang digunakan dalam simulasi adalah Load Case 1 (Gr + Max P). Menurut Tabel 4 bahwa nilai tegangan desain pipa paling tinggi pada node $\mathrm{A} 04 \mathrm{~N}+$ sebesar 6543 psi dan nilai tegangan desain pipa paling rendah pada node A06 N- sebesar 725 psi. Visualisasi tegangan pada node A04 N+ ditunjukkan pada Gambar 5. Node A04 N+ merupakan elbow pipa. Elbow tersebut terjadi pemusatan tegangan akibat tekanan fluida. Dari hasil pemodelan dan simulasi dapat disimpulkan bahwa jalur perpipaan dari reheater menuju feed mixer masih memenuhi kriteria penerimaan dari code ASME B31.3 terlihat pada Gambar 6.

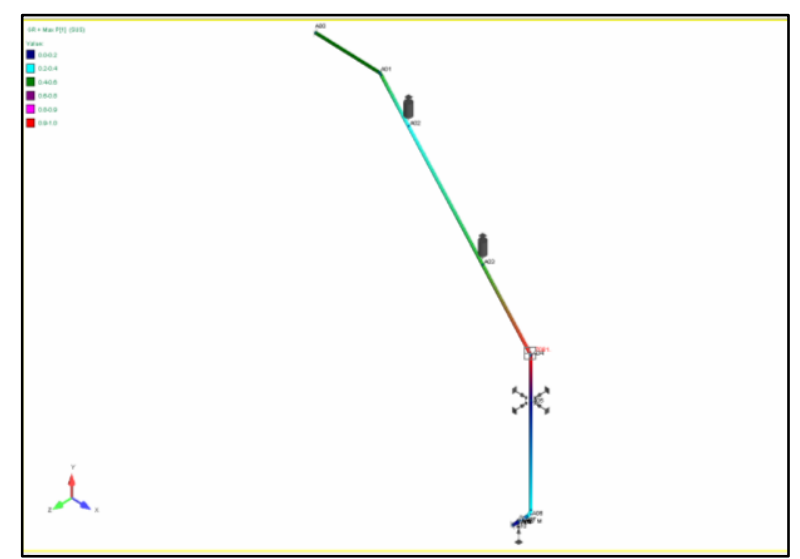

Gambar 4. Pemodelan Jalur Perpipaan Dari Reheater Menuju Feed Mixer

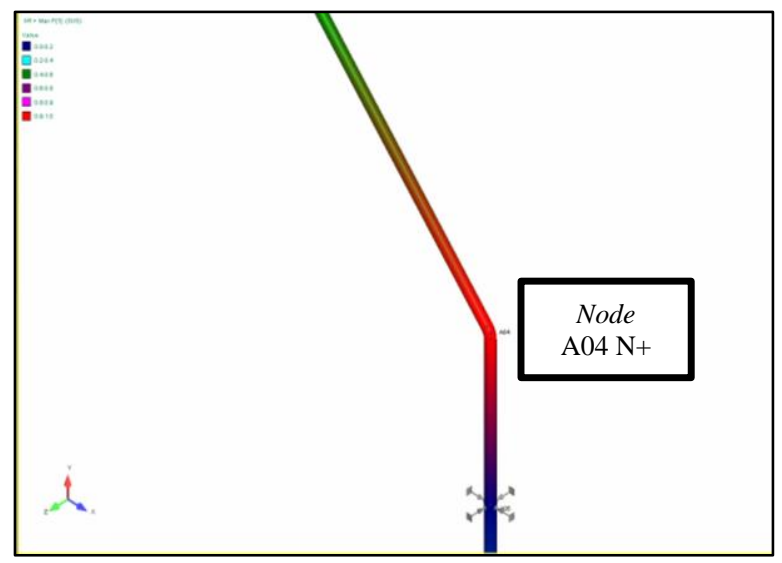

Gambar 5. Visualisasi Tegangan Pipa pada Node A04 N+

Pada Tabel 5 menunjukkan bahwa penyangga yang mengalami pembebanan yang paling besar pada penyangga 2. Penyangga 2 menopang pipa bagian atas sebelum elbow. Elbow tersebut terjadi pemusatan tegangan akibat tekanan fluida sehingga menyebabkan penyangga 2 mengalami pembebanan paling besar yaitu $801 \mathrm{lb}$ dengan defleksi ke arah sumbu x sebesar 0,092 in dan ke arah sumbu z sebesar $-0,396$ in.
Tabel 4. Analisis Tegangan Jalur Perpipaan dari Reheater Menuju Feed Mixer

\begin{tabular}{|c|c|c|c|}
\hline Node & $\begin{array}{c}\text { Tegangan } \\
\text { Code } \text { (psi) }\end{array}$ & $\begin{array}{c}\text { Tegangan } \\
\text { yang diijinkan } \\
\text { (psi) }\end{array}$ & Kriteria \\
\hline A00 & 2464 & 20000 & Diterima \\
\hline A01 N- & 1605 & 20000 & Diterima \\
\hline A01 N+ & 3525 & 20000 & Diterima \\
\hline A01 F- & 3353 & 20000 & Diterima \\
\hline A01 F+ & 1540 & 20000 & Diterima \\
\hline A02 - & 1202 & 20000 & Diterima \\
\hline A02 + & 1266 & 20000 & Diterima \\
\hline A02 - & 2772 & 20000 & Diterima \\
\hline A03 + & 2873 & 20000 & Diterima \\
\hline A04 N- & 2965 & 20000 & Diterima \\
\hline A04 N+ & 6543 & 20000 & Diterima \\
\hline A04 F- & 6486 & 20000 & Diterima \\
\hline A04 F+ & 2927 & 20000 & Diterima \\
\hline A05 & 763 & 20000 & Diterima \\
\hline A06 N- & 725 & 20000 & Diterima \\
\hline A06 N+ & 1623 & 20000 & Diterima \\
\hline
\end{tabular}

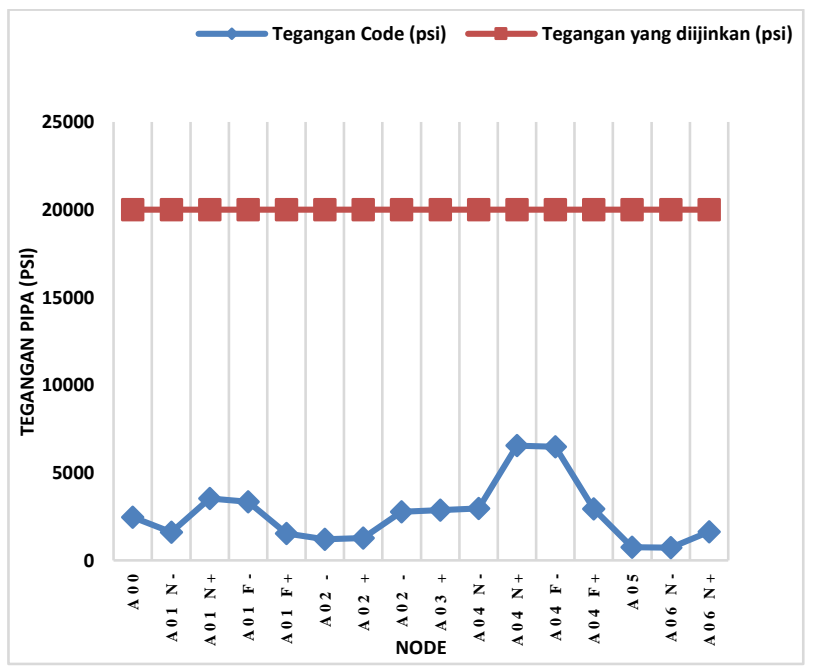

Gambar 6. Tegangan Jalur Perpipaan Dari Reheater Menuju Feed Mixer

Pada Gambar 7 - Gambar 9 menunjukkan gambar visualisasi tegangan pada penyangga pipa.

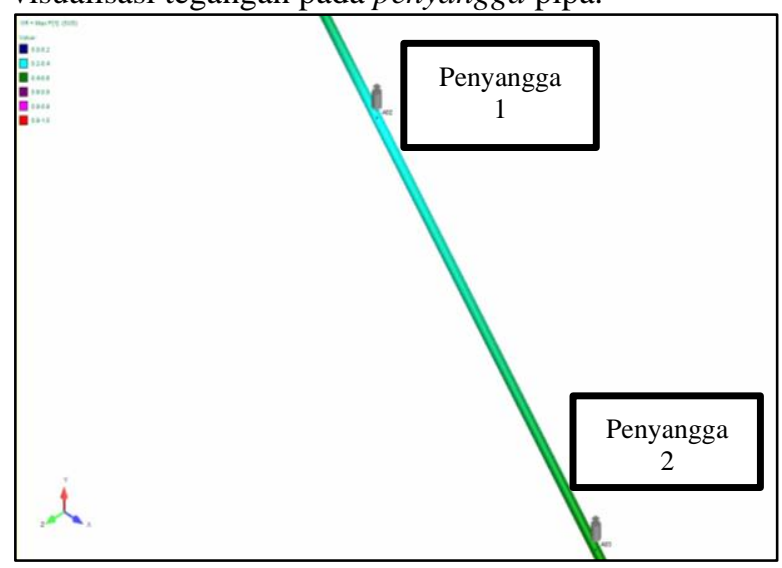

Gambar 7. Visualisasi Tegangan Pada Penyangga 1 dan Penyangga 2 


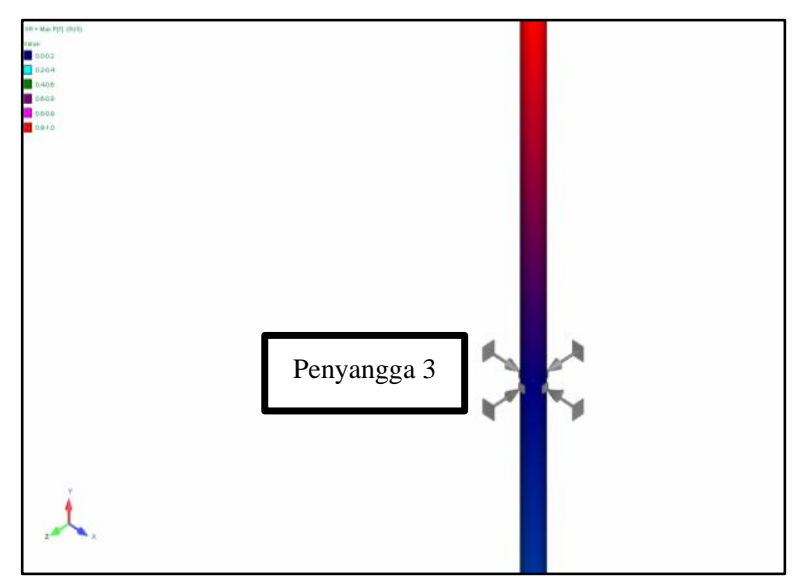

Gambar 8. Visualisasi Tegangan Pada Penyangga 3

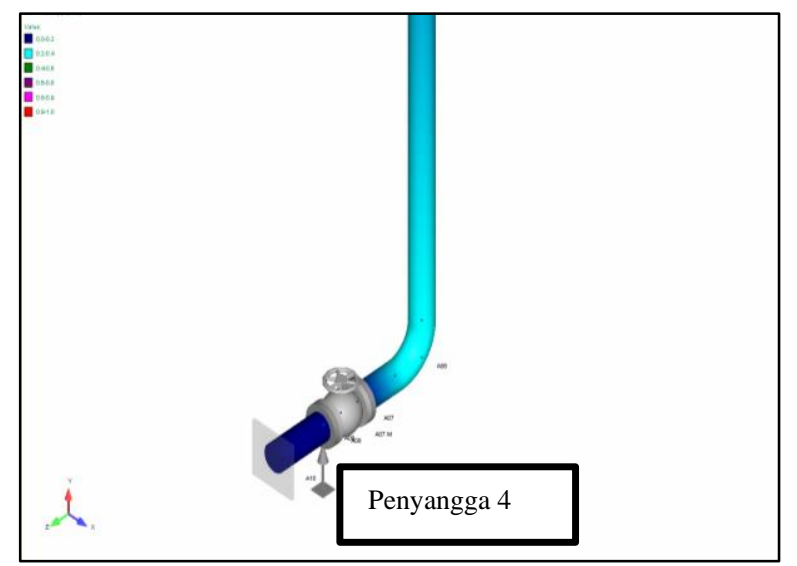

Gambar 9. Visualisasi Tegangan Pada Penyangga 4

Tabel 5. Gaya yang diterima oleh penyangga

\begin{tabular}{|c|c|c|c|}
\hline \multirow{2}{*}{ Penyangga } & \multicolumn{3}{|c|}{ Gaya (lb) } \\
\cline { 2 - 4 } & Sumbu x & Sumbu y & Sumbu z \\
\hline 1 & 0 & -353 & 0 \\
\hline 2 & 0 & -801 & 0 \\
\hline 3 & -243 & 0 & 0 \\
\hline 4 & 0 & -555 & 0 \\
\hline
\end{tabular}

\section{KESIMPULAN}

Dari hasil desain peletakan penyangga dan evaluasi tegangan pada jalur perpipaan dari reheater menuju feed mixer dapat diperoleh kesimpulan sebagai berikut:

a. Jarak maksimum yang diijinkan antar penyangga pipa berdasarkan tegangan yaitu 39,32 ft dan jarak maksimum yang diijinkan antar penyangga pipa berdasarkan defleksi yaitu $24,76 \mathrm{ft}$. Jarak maksimum yang diijinkan antar penyangga pipa yang dipilih yaitu jarak paling kecil sehingga dipilih jarak maksimuk yang diijinkan antar penyangga pipa yang dipilih yaitu $24,76 \mathrm{ft}$. Jarak yang digunakan yaitu $24 \mathrm{ft}$.

b. Nilai tegangan pada desain perpipaan yang paling tinggi berada di node A04 N+ yaitu 6543 psi. Hasil evaluasi menunjukkan bahwa bahwa tegangan pada jalur perpipaan dari reheater menuju feed mixer masih memenuhi kriteria ASME B31.3 karena nilai tegangan desain lebih kecil dari pada nilai tegangan yang diijinkan yaitu 20000 psi.

c. Nilai tegangan pipa desain harus lebih kecil dibandingkan nilai tegangan yang diijinkan oleh code agar jalur/sistem perpipaan lebih aman dari terjadinya kegagalan sistem perpipaan.

\section{DAFTAR PUSTAKA}

ASME. ASME B31.3: Process Piping, ASME Code for Pressure Piping § (2016).

Chamsudi, A. (2005). Diktat-Piping Stress Analysis. Retrieved from https://www.scribd.com/document/25903653 7/Di\%0Aktat-Pipe-Stress-Analysis

Crocker, S. (1945). Piping Handbook Fourth Edition (4th ed.). New York: McGraw Hill Co.

Hasan, M., Santoso, E., \& Mahardhika, P. (2017). DESAIN EXPANSION LOOP PADA LINE 116SV203-150-16H20 FATY ACID DESTILATION PT. WILMAR NABATI INDONESIA. In Proceedings Conference on Piping Engineering and its Application (pp. 31-36). Surabaya: Politeknik Perkapalan Negeri Surabaya. Retrieved from http://journal.ppns.ac.id/index.php/CPEAA/ar ticle/view/387

Kannappan, S. (1986). Introduction to Pipe Stress Analysis. John Wiley \& Sons, Inc.

Kellogg, M. W. (1956). Design of Piping Systems (2nd ed.). Wiley.

Laras, M. B., Santoso, E., \& Ariwiyono, N. (2018). Desain Ulang Sistem Perpipaan Distribusi Fluida Massecuite dari Reheater Menuju Feed Mixer. In Proceeding 3rd Conference of Piping Engineering and its Application (pp. 31-36).

Mahardhika, P. (2017). PENENTUAN ALLOWABLE SPAN ANTAR PENYANGGA PIPA SLF BERDASARKAN TEGANGAN, DEFLEKSI, FREKUENSI ALAMI. Jurnal IPTEK, 21(2), 27-34. https://doi.org/10.31284/j.iptek.2017.v21i2.1 49

Mahardhika, P. (2018). Penerapan metode time history untuk fenomena water hammer. Jurnal Teknologi Maritim, 1(2), 37-44. Retrieved from

http://journal.ppns.ac.id/index.php/teknologi maritim/article/view/432 
Mahardhika, P., Julianto, E., Indartono, A., \& Kusuma, G. E. (2018). ANALISA PENGARUH KENAIKAN TEKANAN FLUIDA TERHADAP TEGANGAN DAN FLEKSIBILITAS PIPA BLOWDOWN A106 GRADE A BERDASARKAN ASME B31.3. TEKNIK, 39(1), 67-72. https://doi.org/10.14710/teknik.v39i1.17118

Okezone.com. (2020). ada 9 pabrik baru indonesia siap swasembada gula pada 2020. Retrieved from

https://economy.okezone.com/read/2019/01/2 8/320/2010200/ada-9-pabrik-baru-indonesiasiap-swasembada-gula-pada-2020

Paul R Smith; Thomas J Van Laan. (1987). Piping and pipe support systems. McGraw-Hill Book Co.

Vakharia, D. P., \& Farooq, M. (2009). Determination of maximum span between pipe supports using maximum bending stress theory. International Journal of Recent Trends in Engineering, 1(6), 46-49. 